\title{
The chronology of basaltic lunar meteorite Northwest Africa 10597
}

\author{
ZEMIN BAO, YuruO ShI*, PeIZHI WANG, XiaOchaO ChE
}

Beijing SHRIMP Center, Institute of Geology, Chinese Academy of Geological Sciences, Beijing, 100037, China,

E-mail: shiyuruo@bjshrimp.cn (Yuruo Shi)

Introduction: The lunar meteorite NWA 10597 is unbrecciated basalt, which is one of the representative meteorites of young and evolved lunar volcanic rocks [1]. NWA 10597 has been reported paired with NWA 4734 [2], which shows a large age range from $2720 \mathrm{Ma}$ to $3083 \mathrm{Ma}$ [3-5]. In this study, we carried out a detailed investigation on the $\mathrm{U}-\mathrm{Pb}$ isotopic age of the lunar basalt.

Method: The U-bearing accessory minerals of NWA 10597 are mainly Ca-phosphate (apatite and merrillite). In-situ U-Pb dating analysis was performed on a Sensitive High Resolution Ion Micro Probe (SHRIMP II) . In order to increase the stability of the dating, a Kohler focusing mode was used to o btain a uniformdensity beam size of $\sim 10 \mu \mathrm{m}$.

Results: The results show that the ${ }^{207} \mathrm{~Pb} /{ }^{206} \mathrm{~Pb}$ ages of phosphates range from $2980 \mathrm{Ma}$ to $3300 \mathrm{Ma}$, with 4 peak ages of $\sim 3010 \mathrm{Ma}, \sim 3060 \mathrm{Ma}, \sim 3130 \mathrm{Ma}$, and $\sim 3180 \mathrm{Ma}$. Moreover, there are also 4 analyses that reveal ages between $3200 \mathrm{Ma}$ and $3300 \mathrm{Ma}$.

Discussion \& conclusions: The ages of $\sim 3010 \mathrm{Ma}, \sim 3060 \mathrm{Ma}$, $\sim 3130 \mathrm{Ma}$, and $\sim 3180$ Ma suggest four episodic magmatisms. The youngest $\mathrm{Pb}-\mathrm{Pb}$ age of $\sim 3010 \mathrm{Ma}$ reflects the final crystallization time of the meteorite. However, the ages between $3200 \mathrm{Ma}$ and 3300 Ma represent older thermal events.

References: [1] Chen J., et al. 2019. J. Geophys. Res.: Planets, 124: 2583-2598. [2] Wu Y., et al. 2020. Icarus, 338: 113531. [3] Wang Y., et al. 2012. Geochim. Cosmochim. Acta, 92 : 329-344. [4] Fernandes V. A., et al. 2009, Lunar Planet. Sci. $40^{\text {th }}$ Abstract \#1045. [5] Elardo S. M. et al. 2014. Meteorit. \& Planet. Sci. 49: 261-291 